\title{
DETECTING LAND USE/COVER DYNAMICS AND LAND SUITABILITY MAPPING FOR IRBID GOVERNORATE USING AN INTEGRATED APPROACH
}

\author{
Alsharifa Hind MOHAMMAD ${ }^{1}$, Taleb ODEH ${ }^{2}$, Maha HALALSHEH $^{1}$, \\ Khaldoun SHATANAWI ${ }^{1,3}$ \\ ${ }^{1}$ Water, Energy and Environment Centre, The University of Jordan, Amman, Jordan \\ ${ }^{2}$ Department of Earth and Environmental Sciences, The Hashemite University, Zarqa, Jordan \\ ${ }^{3}$ School of Engineering, The University of Jordan, Amman, Jordan \\ Received 06 December 2020; accepted 26 January 2021
}

\begin{abstract}
Highlights
Changes results showed an increase in urban land, from 2\% in 1985 reached $11 \%$ in 2015; soil and agricultural classes had declined, in 1985 they were $74 \%$ of the total area, and reduced to $67 \%$ in 2015 .

> Irbid Governorate's change detection results revealed that the decline of agriculture and rock land areas is due to the accelerated expansion of urbanization, which negatively affects agricultural lands.

Modelling the area showed high suitability for agricultural activities, which should be considered for the upcoming plans.
\end{abstract}

\begin{abstract}
This research proposes to design an approach recognizing land use/cover change for Irbid governorate from 1985 to 2015 in 10 years period bases, with an agriculture suitability map using remote sensing and GIS. In this paper, ENVI6 was used to analyse Landsat images, which helps to understand the land uses' classes. LULC Changes results showed an increase in urban land, from $2 \%$ in 1985 reached to $11 \%$ in 2015; soil and agricultural classes had declined, in 1985 they were $74 \%$ of the total area, and reduced to $67 \%$ in 2015 . Irbid Governorate's change detection results revealed that the decline of agriculture and rock land areas is due to the accelerated expansion of urbanization, which negatively affects agricultural lands. Modelling the area showed high suitability for agricultural activities, which should be considered for the upcoming plans.
\end{abstract}

Keywords: land use/cover (LULC), Irbid, Landsat 5, 7, ENVI, remote sensing, suitability map.

\section{Introduction}

Jordan is an arid to semi-arid Mediterranean country, with an area around $89,000 \mathrm{~km}^{2}$. The average annual rainfall ranges from less than $20 \mathrm{~mm}$ in the Badia region up to more than $600 \mathrm{~mm}$ along the western mountains (Mohammad et al., 2015). Jordan is on the top of water-poor countries worldwide, which adds enormous pressure on social and economic development; Jordan's decision-makers have been long pressured to find a sustainable solution to the environmental situation facing the country (Mohammad et al., 2020). Irbid governorate is one of the population-densest Jordanians' governorates; it has an area of about $1572 \mathrm{~km}^{2}$ (Figure 1a). The high tectonic activities in Irbid governorate increased the topography variation (Bender, 1974; Odeh et al., 2017, 2019) (Figure 1b), which positively affects the rainfall pattern in the area as shown in Figure 2. Wise natural resources management is the most intelligent solution for the economic and environmental setting, especially in developing areas; this is because it enhances more balance and integration between environmental elements. Because of increasing human activities, environmental problem has become widespread in many parts of the world. The deterioration in environmental quality and widespread environmental degradation (biological and chemical) by air and water pollution and soil and vegetation loss can result in negative ecological

${ }^{*}$ Corresponding author. E-mail: s.jasem@ju.edu.jo 

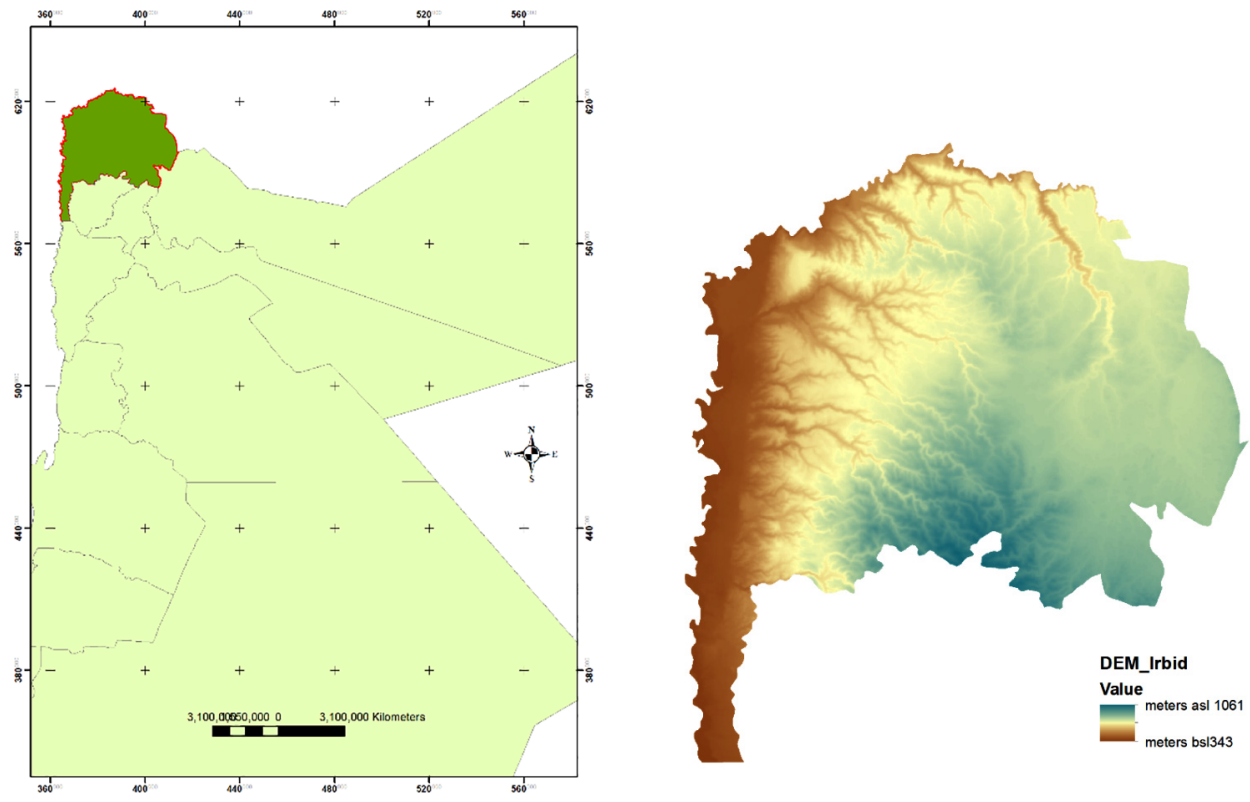

Figure 1. Location of the targeted area (a); DEM for Irbid area (b)

and health consequences (Basheer, 2017; Basheer \& Ali, 2018; Alharbi et al., 2018; Ali et al., 2013, 2017; Dunlap \& Jorgenson, 2012; Yohannes, et al., 2020). Land use and land cover concepts are usually used conversely; nevertheless, each term has its sole meaning. Land cover ordinarily refers to the features and surface cover of Earth's surface represented by natural elements such as vegetation, water, bare land, impervious surface, and other land's physical features. In comparison, land use refers to activities with an economic purpose, intended use, or management strategy placed on humans' land. It could also be defined as Land use, in general, refers to human activity on a land surface, and land cover refers to its surface features

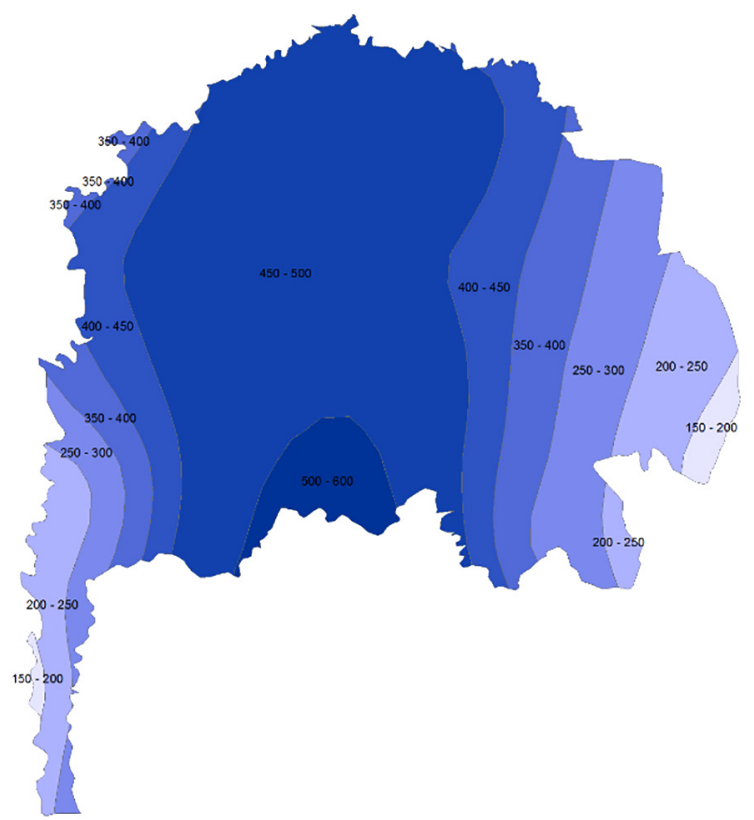

Figure 2. Rainfall distribution of Irbid governorate
(Lambin \& Meyfroidt, 2010). LULC change detection is an essential tool to identify geographical dynamics and the association with human activities (Yohannes et al., 2020). LULC classification maps should be determined because of their importance in decreasing the negative effects of human activities on nature (Gülersoy et al., 2015). Exploring land use and land cover (LULC) changes is essential for planning and utilizing natural resources, which positively strengthens the decision-making process and, hence, achieves sustainable development goals. Also, LULC studies are very effective to evaluate temporal changes of land use in the protection of certain area in terms of sustainable use of natural resources (Gülersoy \& Çelik, 2017).

This study examines land use/cover change dynamic patterns in Irbid governorate from 1985 to 2015 using satellite imagery data with the Geographic Information Systems technique (GIS). Studying the LULC change is said to be as an important tool to define parameters which are responsible for different changes of land surface; such as but not limited to: landscape changes, changes in ecosystems, climate changes effects, and urban areas expanding. Because of the increasing development and the rapid growing in population worldwide, many countries in the world faced wide changes in LULC; this came in parallel with an increase in anthropogenic activities, and hence resulted in high alteration LULC, which lead to forest deterioration in some areas and transformation of fertile land to urban construction with significant impact on the ecosystem in other regions. In order to detect the changes that have been occurred; and develop a framework of LCLU changes research in Jordan; optical remote sensing data and GIS software were integrated to explore the potential of these techniques to define LCLU changes within the current urban planning system and the better management for the natural resources. The importance of 
the LULC application of Irbid is the reason for choosing it as a study area. It is necessary to mention that Irbid governorate has the highest population density in Jordan according to the governmental records, and it is the second-largest population in Jordan (Department of Statistics, 2014). It has also received several immigration waves during recent history; a wave of Palestinian refugees was in 1948 after the first Arab-Israeli. Another wave was in 1967 when thousands of Palestinian refugees came to Jordan and settled in different Jordanian governorates and Irbid as well (Perdew, 2014).

Furthermore, other migrations came to Irbid after the Gulf wars in 1991 and 2003. Similarly, more than half a million Syrian refugees came to Irbid since 2011 due to the Syrian civil war. This immigration raised the annual population growth rate in Irbid; it is worth to mention that the governorate has one of the highest growth rates in the region with 3.2\% (Department of Statistics, 2014; Perdew, 2014; Odeh et al., 2019). The increased number of population and the expansion of urban areas increase the change of the LULC concept. LCLU studies for Irbid governorate was note detected before, this study shaded the light on the importance of the smart planning and focus on the behaviour of the people there toward land use.

Hydro-geologically, the study area involves two main aquifer systems; the Umm Rijam and Wadi Shallala (B4/ B5) Aquifer system and the Upper Cretaceous AmmanWadi Assir B2_A7 Aquifer system (Margane et al., 1999; Figure 3). The upper aquifer crops out in northern areas of Irbid towards the Yarmouk River. The B4 formation comprises marly and chalky limestone and chert while the B5 formation consists of chalky and marly limestone (Hobler et al., 2001). The Umm Rijam formation is the outcropped unconfined aquifer underlain by the Muwaqqar Chalk Marl formation (B3). In the southern parts of Irbid governorate, the massive limestone, dolomitic limestone and

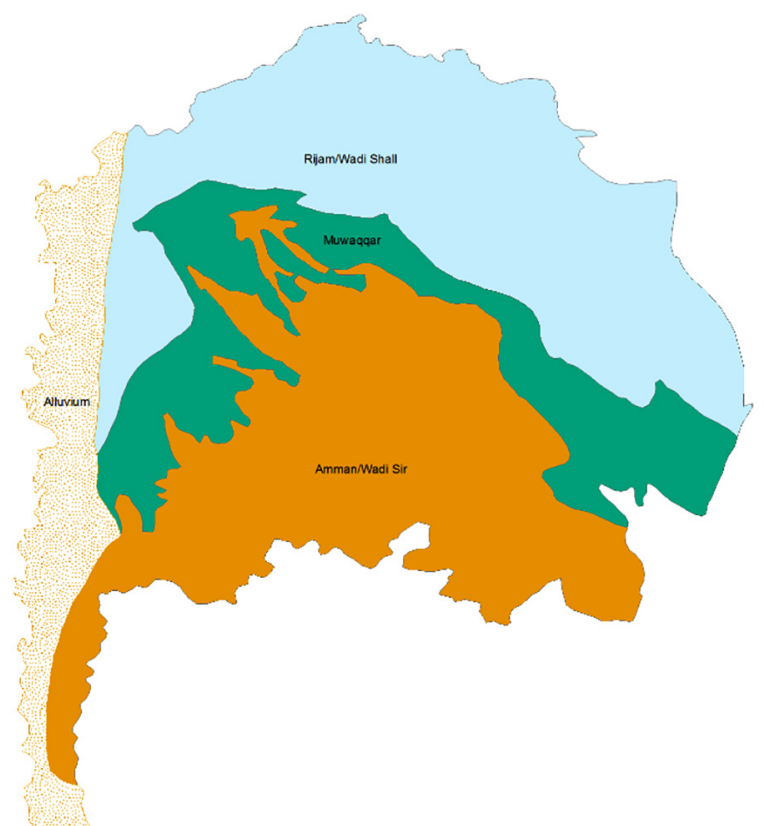

Figure 3. Hydrogeological units for Irbid area chert A7/B2 aquifer form the primary aquifer in Irbid; this aquifer used to be the primary aquifer in Jordan as well, but now most of the wells in the area are dropped and no longer used for drinking water purposes because of either of the decreasing yield or deterioration of water quality or both of the problems.

\section{Materials and methods}

The procedure of integrating remote sensing (RS) methods and the geographic information system (GIS) is broadly used to investigate, analyse, and display land surface data (Saraf et al., 2004; Odeh et al., 2013, 2019). The RS methods essentially produce the land cover data in satellite images, usually classified as creating different land cover classes. GIS is a useful tool to produce thematic maps; thus, it was required to merge new technologies such as remote sensing and GIS tools to support environmental studies (Mohammad et al., 2018). For reliable LULC mapping, selection of appropriate remotely sensed datasets and choice of a suitable classification system are considered the two most important factors (Lu \& Weng, 2007; Abdulla et al., 2019). Landsat remote sensing data considered the most comprehensive continuously obtained collection of space-based moderate-resolution data worldwide. Forty years of satellite images provide an adequate data resource for remote sensing researchers. The acquired data usually originates as a raster dataset, which then becomes analyzed using GIS tools. It can produce repetitive observations of the land surface, giving information about land cover changes over time (Odeh et al., 2019). In Jordan, many studies applied the LULC concept (Al-Mashagbah \& Al-Adamat, 2010; Rababa’a \& Al-Bakri, 2006; Al-Sallal \& Al-Bilbisi, 2011), and others applied different Landsat and satellite imagery to analyze LULC in the country. Policymakers inquire data on the LULC change to develop more specific policies and management guidelines that focus on causes, not symptoms. It is a fact that processes that driving LULC change are complicated, occurring at several temporal and spatial scales, with interconnections of various environmental, social, and economic impacts, and they require several methods of investigation to understand the drivers and their impact on the environment, landscapes, and rural societies (Lambin \& Meyfroidt, 2010). Classical methods for collecting and analyzing environmental data are not adequate; meanwhile, additional methods could be used to achieve the goal.

Landsat 5 images were utilized to investigate different targeted years; 1985, 1995, and 2005, and Landsat $7 \mathrm{im}$ agery was applied for 2015 depending on the data's availability. The US Geological Survey web site (https://landsat. usgs.gov/lands at-data-access) was the open-source for the Landsat images used in this research. The software ENVI 6; is a package broadly used by GIS and RS specialists to process images; it is used to extract essential data about land surface classes acquired from satellite imagery (Saraf et al., 2004). In this study, Landsat data were used to classify land coverage into four classes: soil units, rock units, 
urban land, and agricultural land. Land coverage classifications were verified with field visits, Google Earth imagery for 2005 and 1995, and the 1985 Landsat images. Thematic maps were prepared, which is the most famous tool used to understand specific phenomena' spatial distributions (Li \& Chou, 1997). The preprocessing stage for the images was starting with calibration, atmospheric correction, and topographic correction. selection of dates of the acquired data had made in the dry season and with the same annual season of the acquired years to avoid the seasonal variation and to minimize the error occured by clouds. All the used satellite images was analyzed using the RGB colour composition using ENVI 6 software. The goal of this is to determine which land-use class is changing using image overlay method, in addition to the classification comparisons of land cover analysis.

Land cover mapping is a process which conducted into many phases; starting with the preparation for the work, this is based on image extraction from the source (the website in this case). Then, the interpolation process started by an atmospheric correction to minimize the effects of cloud and smoke in the images. During the other phases, a spectral measurements were established, in which identified the pure spectral components for the calculation in each pixel within the each image. Changes in land use and land cover were analysed by 10 years sequence, which was described through the analysis of a temporal series of classified images. The LULC mapping was created at the pixel level using a function ArcGIS, where different landuse maps were combined into a single map.

In parallel, this study focuses on determining the geospatial variables of Irbid area for the agricultural suitability; four levels of FAO land suitability classes are shown in Table 1 (Food and Agriculture Organization of the United Nations [FAO], 1976, 1983, 2007). The concept of land suitability evaluation for agricultural land-use planning in the study area is defined using the FAO measure. According to FAO, suitability mapping is defined as the requirements and land properties for a particular activity that measures how the characteristics of land suit the

Table 1. Land suitability classes for each limitation of different land utilization

\begin{tabular}{|l|c|l|}
\hline Suitability class & Code & \multicolumn{1}{|c|}{ Description of limitation } \\
\hline Highly Suitable & S1 & $\begin{array}{l}\text { Land having no significant or only } \\
\text { minor limitation }\end{array}$ \\
\hline $\begin{array}{l}\text { Moderately } \\
\text { Suitable }\end{array}$ & S2 & $\begin{array}{l}\text { Land having limitations which in } \\
\text { aggregate are moderately severe for } \\
\text { sustained application }\end{array}$ \\
\hline $\begin{array}{l}\text { Marginally } \\
\text { Suitable }\end{array}$ & S3 & $\begin{array}{l}\text { Land having limitations which in } \\
\text { aggregate are severe for sustained } \\
\text { application }\end{array}$ \\
\hline Not Suitable & NS & $\begin{array}{l}\text { Land having limitations which may } \\
\text { be surmountable in time but which } \\
\text { cannot be corrected with existing } \\
\text { knowledge at currently acceptable } \\
\text { cost }\end{array}$ \\
\hline
\end{tabular}

requirements of a particular form of land use (FAO, 1993, 1985; De la Rosa et al., 1981; Sys, 1975; Joerin et al., 2001; Sys et al., 1993). In suitability mapping, modelling all possible influential factors is involved; those that influence the process using multi-criteria evaluation generate the final land suitability map. Mapping agricultural suitability is very useful for locating and ranking areas expected to be high or less suitable, practically in an arid land (Abd El-Kawy et al., 2010; ElSheik et al., 2010; AlFarajat et al., 2015). The index was prepared based on the merging of hydro-geo-environmental parameters including; rainfall, slope percentage, soil types, groundwater quality, and depth records (Mazahreh et al., 2018; Al Farajat et al., 2015), modeling these maps resulting in creating the final agricultural suitability map for the targeted area.

\section{Discussion and results}

The fluctuations in LULC change observed during the study period are undoubtedly associated with rapid population growth. A decline in soil fertility, resulting from intensive farming, has also forced farmers to expand their activities, land reallocation for cultivation and settlement (especially for the younger generation) appeared to have influenced this phenomenon.

Landsat images analysis showed significant random variations from 1985-2015 as shown in Figure 4. Urbanized area growth has developed nine times over the 30 years, and it is prompted due to the increase of population. Meanwhile, the agricultural areas declined during the first ten years of the study period due to the migration of youth from rural areas to the cities searching for jobs (US Department of Agriculture, 1993; Department of Statistics, 2014; Perdew, 2014). However, in the next 20 -year period (1995-2015), the agricultural sector witnessed rising rates; this might be because of turning the youth back after finding no suitable jobs in the cities. The research reached the point that the percentage of the fluctuation rates in the agricultural cover is changed with the soil cover areas; when the decrease occurs in agricultural activities, the increase occurs in the soil covered areas (Figure 5). The urbanization expansion influences the barred rock area in the study area; however, in the last ten years of the targeted period, the rock outcropped area has increased by about $1 \%$ because of the natural soil erosion in the study area. As urbanization has an apparent trend in landuse change, a chart was created to plot the percentages for the urbanization activities during 1985-2015. The trend shows a linear correlation between the years and the percentage of urban land cover; extending the chart to the next 30 years gives a prediction of increasing the land use for urbanization to reach $21 \%$ of the total area in 2054 (Figure 6).

Percentages of each class of landuse map for every year were drawn as a pie chart to bitter understand the changes of the landuse over that period; Figure 7 shows the resulted charts; it concludes that the significant changes in the landuse are in the soil cover and urbanization activities within the governorate, and that the urbanization 

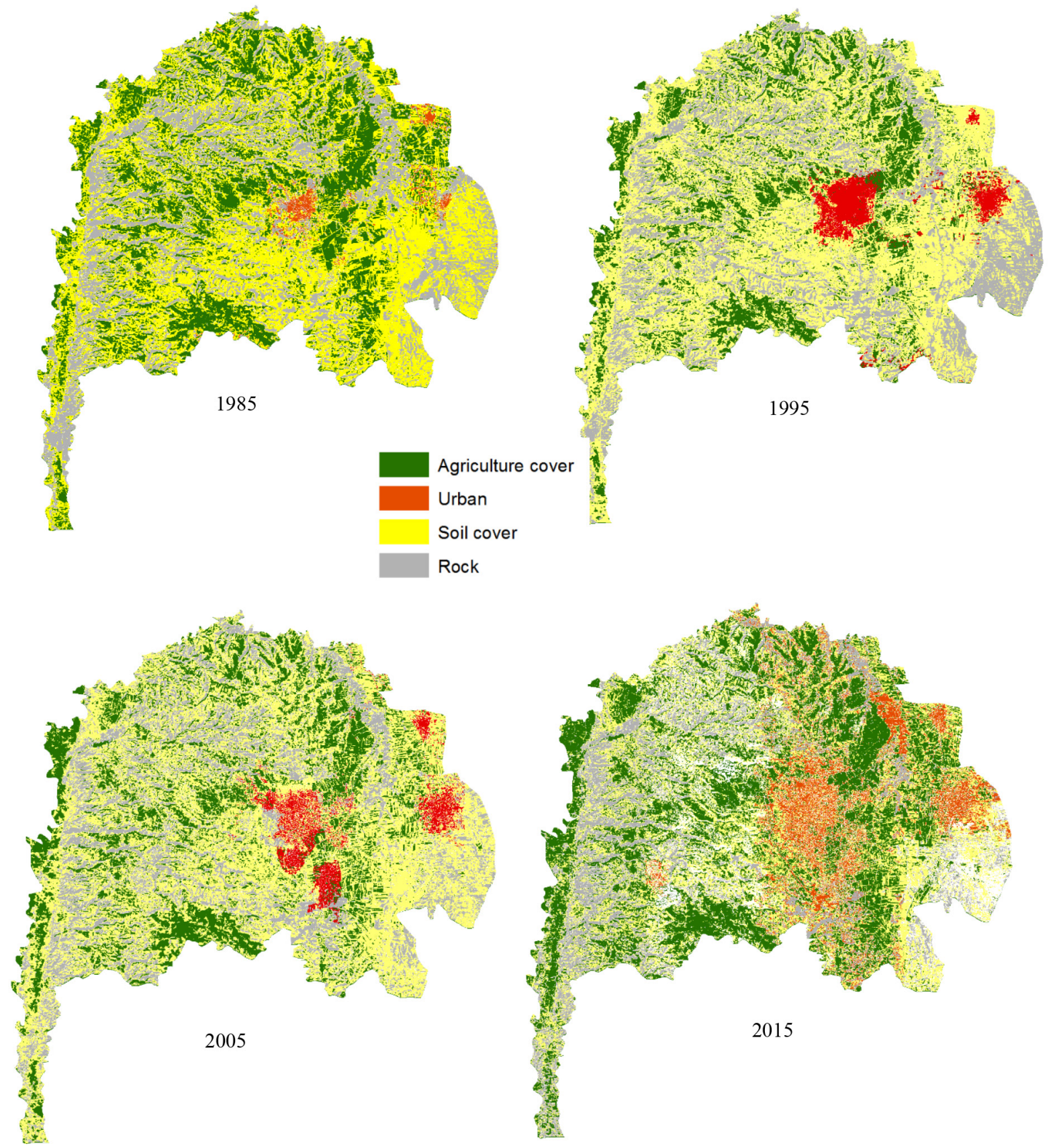

Figure 4. Landuse classifications for the targeted years in Irbid governorate

Soil/ Agricultural cover

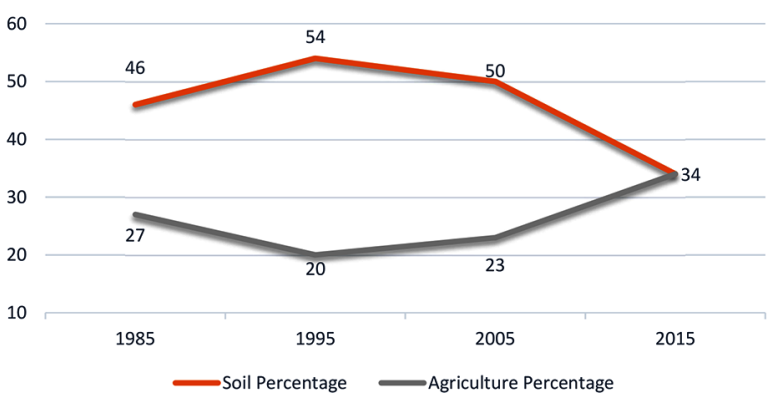

Figure 5. Soil cover to Agricultural cover ratios
Urbanization Prediction

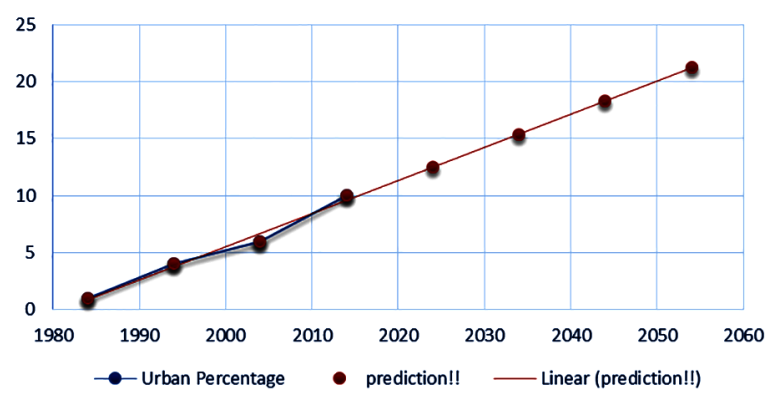

Figure 6. Urbanization prediction according to the landuse maps for the coming 20 years 

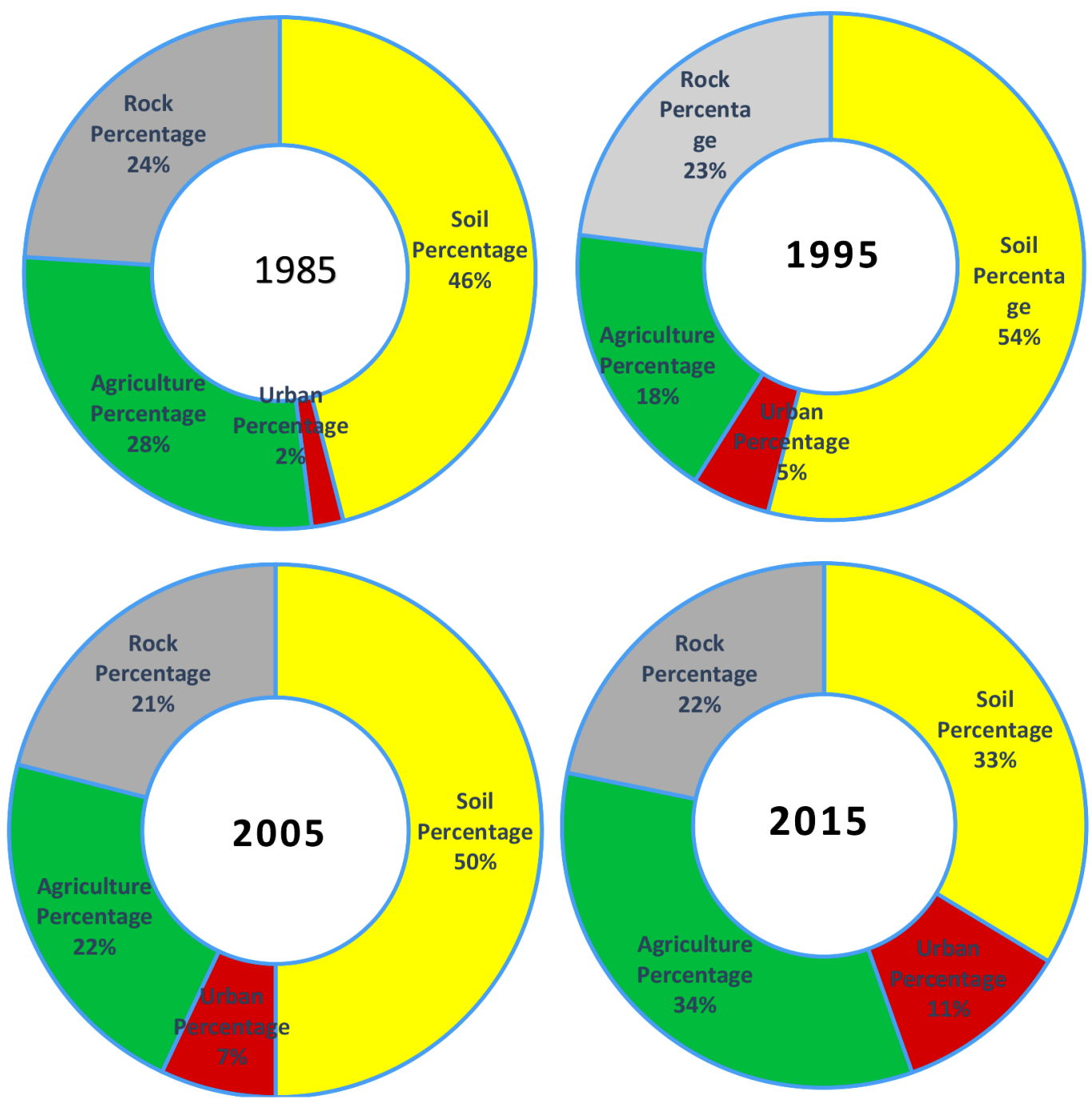

Figure 7. Land use classification percentages in 4 different years

increased from $2 \%$ up to $11 \%$ while the soil decreased from $46 \%$ to reach $33 \%$ in the year 2015 .

An examination of LULC change over the study period highlighted substantial loss of natural and semi-natural landscape units and expansion of a human dominated landscape. These changes have the potential to affect land productivity, habitat quality, ecological processes and functions, ecological resilience, and ultimately, general human well-being. Future land use management plans based on simulated LULC maps may prove important in reducing pressure on natural ecosystems and assist in minimizing the expansion of human land-use activities, thereby reducing or eliminating any further degradation of ecosystem functionality.

Land suitability map for Irbid was generated based on the different criteria for agricultural land suitability; the criteria were classified into four levels in Table 1. Overlay tool was applied to produce the suitability map; this started by mapping the rainfall; according to (Ministry of Water and Irrigation [MWI], 2010), the mean annual rainfall ranges between $150 \mathrm{~mm}$ in the eastern and western parts to $650 \mathrm{~mm}$ in the western part of the governorate as the historical records of the Ministry of Water and Irrigation, records were mapped using krigging method under the GIS softwater to produce the thematic map of this factor, as shown in Figure 2 above, the rainfall map was modelled as a suitability factor map according to Table 2 to produce the map shown in Figure 8a. This figure shows that most of the area has high rainfall suitability for agricultural

Table 2. Land suitability for agriculture criteria

\begin{tabular}{|l|c|c|c|c|}
\hline \multirow{2}{*}{$\begin{array}{c}\text { Environmental } \\
\text { factor }\end{array}$} & \multicolumn{4}{c|}{ Suitability class } \\
\cline { 2 - 5 } & S1 & S2 & S3 & NS \\
\hline Value & 4 & 3 & 2 & 1 \\
\hline Rainfall (mm/yr) & $>250$ & $200-250$ & $150-200$ & $<150$ \\
\hline Soil permeability & High & Medium & Low & Very law \\
\hline Slope \% & $<15$ & $8-15$ & $5-8$ & $>5$ \\
\hline Depth to water $(\mathrm{m})$ & $<100$ & $100-150$ & $150-250$ & $>250$ \\
\hline GW salinity $(\mathrm{ppm})$ & $<700$ & $700-1000$ & $1000-1500$ & $>1500$ \\
\hline
\end{tabular}



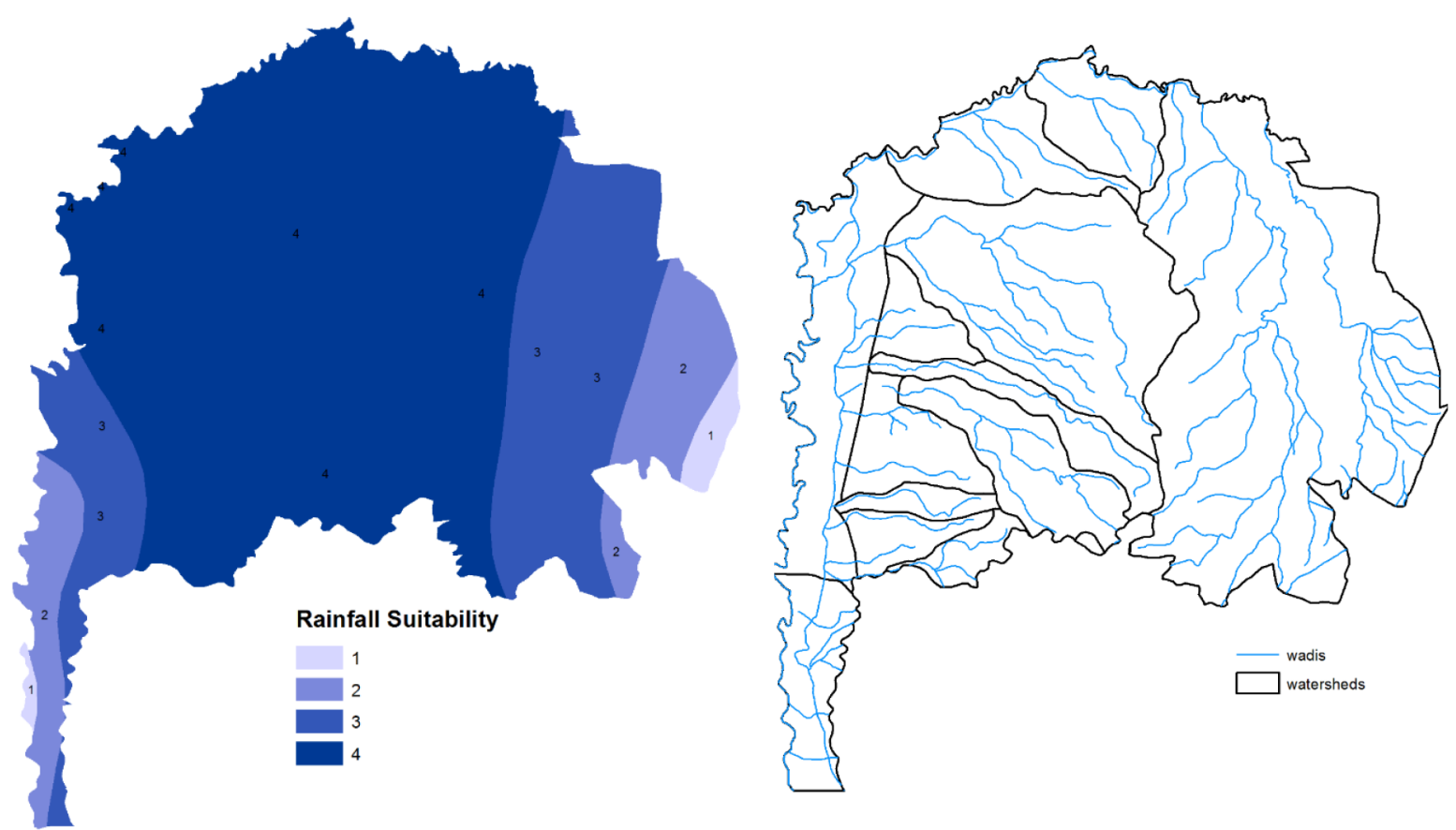

Figure 8. Rain suitability map for the area (a); Watersheds in Irbid (b)

activities. Rainfall distribution and amount are other vital factors that affect agricultural suitability. A watershed is an area that naturally drains water into a specific water body; watersheds drain rainfall and snowmelt into streams and rivers, Digital Elevation Model (DEM) for the targeted area was used to develop this map using the Hydrology tool under the GIS software. Figure $8 \mathrm{~b}$ shows the different watersheds within Irbid governorate. Aspect maps represent the horizontal orientation of a surface and are determined in units of degrees.

According to Figure 1b, the study's area DEM, it is found that the area's topography ranges from $340 \mathrm{~m}$ below sea level to $1060 \mathrm{~m}$ above sea level. Building the aspect model was created to determine the exposure amounts of sunshine over the targeted area, the aspect model was derived using the DEM under the GIS software, Figure 9a shows aspect map for Irbid. A slope percentages map was also derived from DEM; the slope percentage dataset was processed and divided the area into different categories according to (Mazahreh et al., 2018) for representing levels of slope suitability for agriculture (Farhan \& Al-Bakri, 2012) as shown in Figure 9b.

Depth to Groundwater refers to the distance between the water table and ground surface, different well records collected from the MWI (2016) for developing the needed map using the same krigging method by GIS software (Figure 10a), depths to water table in the targeted area ranges from 100 to $300 \mathrm{~m}$, areas with shallower water table
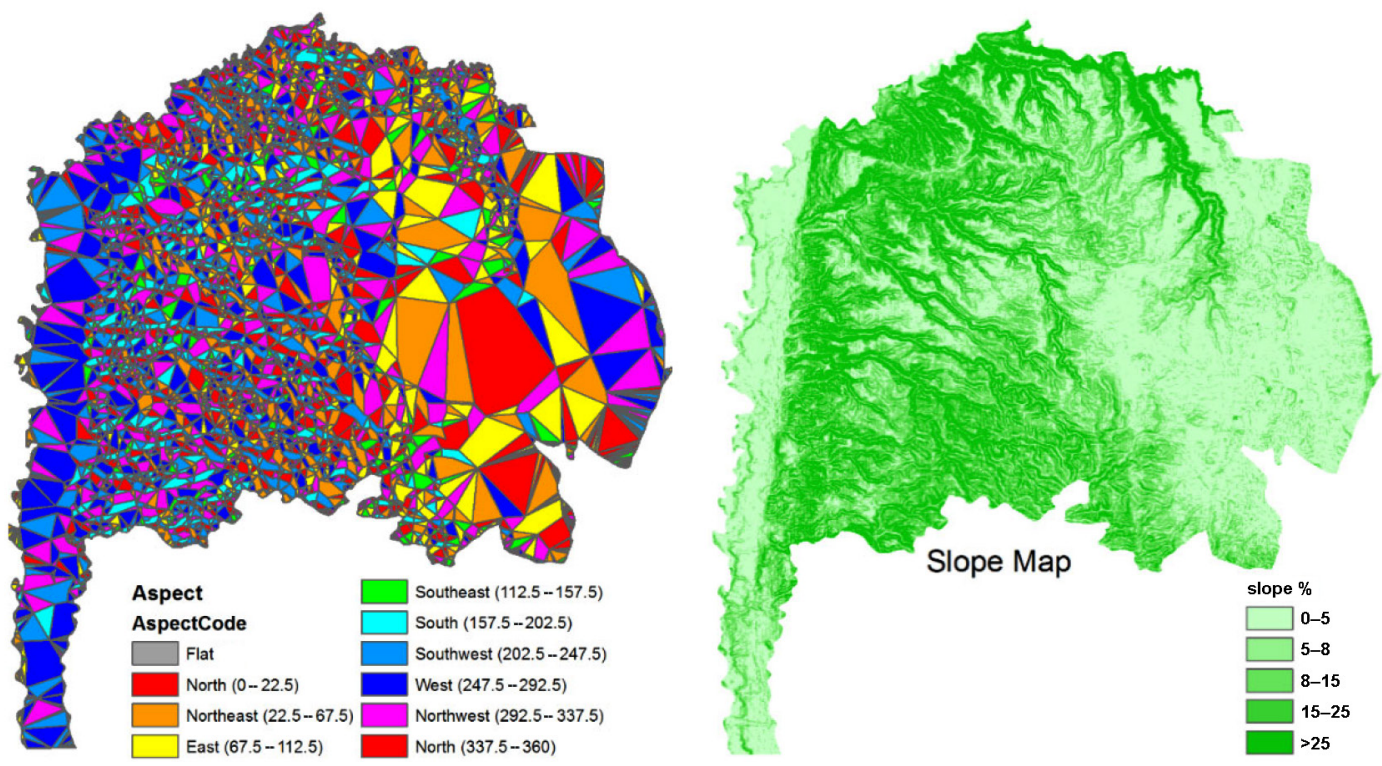

Figure 9. Aspect mp for Irbid area (a); Slope map for the area (b) 

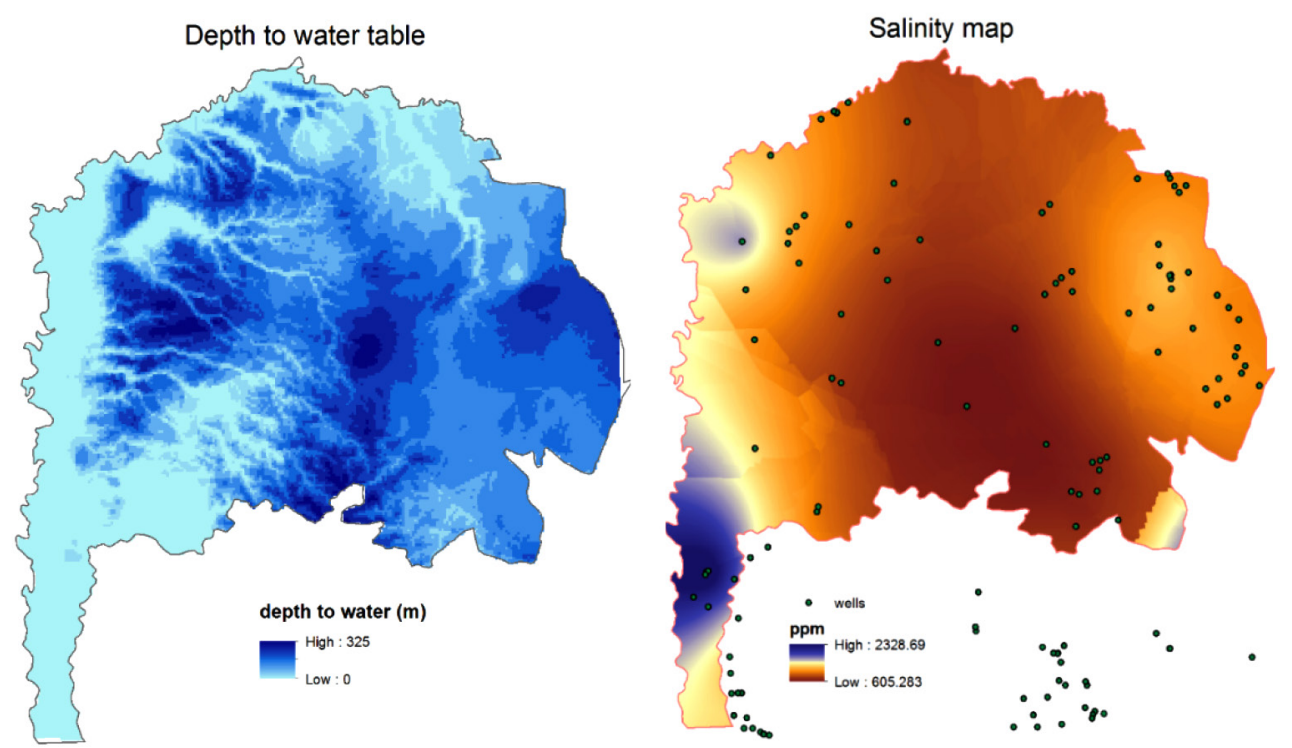

Figure 10. Depth to water table in Irbid (a); Salinity map for grounswater in Irbid area (b)
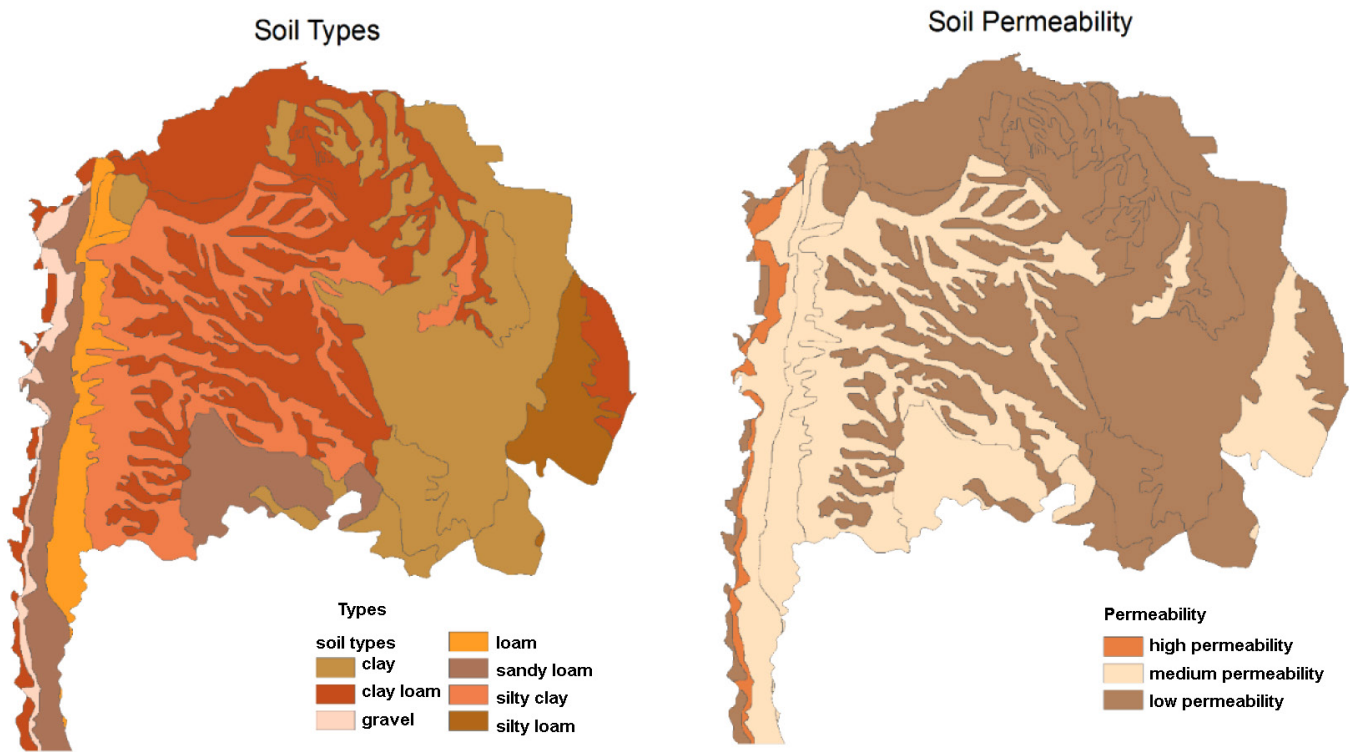

Figure 11. Soil types in Irbid (a); Soil Permeability classes in Irbid area (b)

reflect higher suitability classes. Water quality is another factor that includes in the index, it reflects the salinity of the water which might be used for irrigation. A salinity map for the targeted area was modelled by testing the water samples collected from groundwater wells located within the study area (MWI, 2016). The salinity records in the aquifers in Irbid area range from 660 to $2400 \mathrm{ppm}$, as shown in Figure 10b.

Soils in the targeted area are classified into three classes according to its permeability properties as shown in Figure 11a, high permeability classes; which includes the gravel soil, this soil is existing in the western parts of the area. Medium permeability soils with main great groups of loam, silt clay, sandy loam, clay loam soils, and Low permeability soils, containing the clay and clay loam soils, perm ability classes are shown in Figure 11b.

Applying the principle for the Agricultural Suitability Map; merges all the primary factors that affect the agricultural activities and the suitability index was reached in this study (Table 2). The final agricultural suitability map is shown in Figure 12. According to the model, the targeted area divided into four main classes: the low suitability class, which covered $5.8 \%$ of the governorate's total area, $43.4 \%$ of the total area was reflecting the medium suitability class. In contrast, $49 \%$ of the total area reflected the high suitability class, and $1.8 \%$ of the area was very high suitable for agricultural activities. 


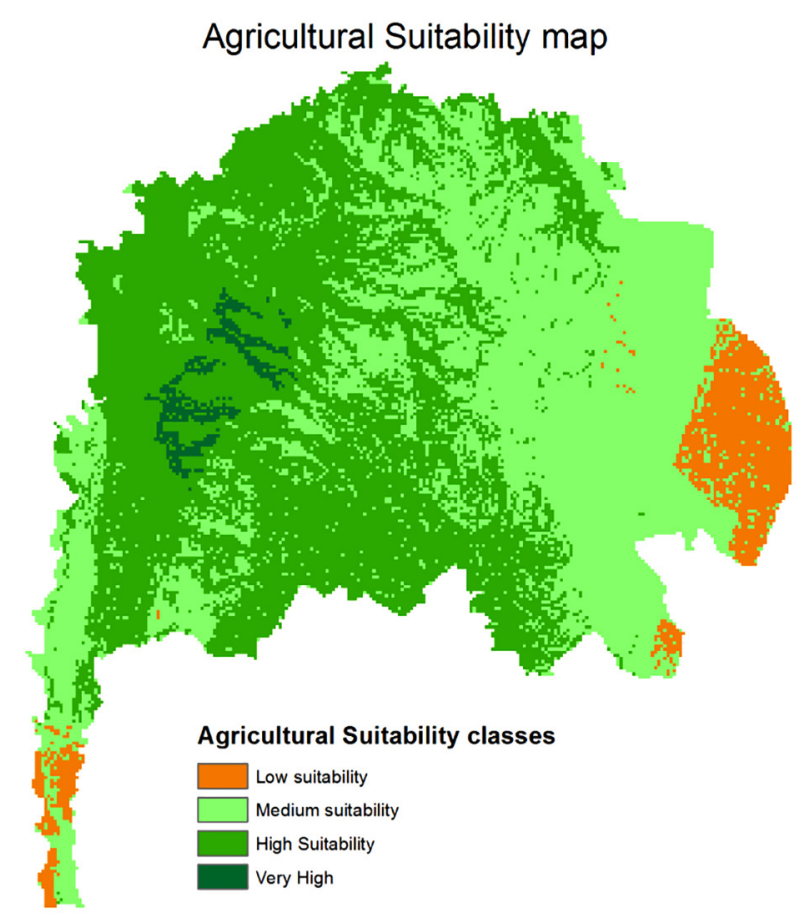

Figure 12. Final Agricultural suitability map for Irbid

\section{Conclusions}

This paper focuses on LULC changes in Irbid Governorate, Jordan, using remote sensing data and GIS technology. Results show that LULC changes were significant during the period from 1985 to 2015 . There is a notable increase in urban areas. On the other hand, there are fluctuations in agricultural areas, barren rocks, and soil areas. This paper indicates the impact of population on LULC change. The study also confirms that integrating GIS and remote sensing technologies is a valuable tool for urban planning and management. Through the research, a suitability index for agricultural lands suggested in this study uses different geospatial factors. The generated map shows that most of the Irbid governorate area is classified as medium to high suitability for agriculture; this raises the importance of applying the LCLU models to protect those areas, here it should be noticed that the landuse must be governed in order to reduce losing the agricultural areas.

However, it worth to mention that the index still requires more validation and development, which is recommended in this study.

\section{References}

Abd El-Kawy, O. R., Ismail, H. A., Rod, J. K., \& Suliman, A. S. (2010). A developed GIS-based land evaluation model for agricultural land suitability assessments in arid and semiarid regions research. Research Journal of Agriculture and Biological Sciences, 6(5), 589-599. https://www.researchgate. net/publication/316513719_A_Developed_GIS-based_Land_ Evaluation_Model_for_Agricultural_Land_Suitability_Assessments_in_Arid_and_Semi_Arid_Regions

Abdullah, A. Y. M., Masrur, A., Adnan, M. S. G., Al Baky, Md. A., Hassan, Q. K., \& Dewan, A. (2019). Spatio-temporal patterns of land use/land cover change in the heterogeneous coastal region of Bangladesh between 1990 and 2017. Remote Sensing, 11(7), 790. https://doi.org/10.3390/rs11070790

Al Farajat, M., Mohammad, A. H., Diabat, A., \& Al Ibraheem, H. (2015). Developing a land suitability index for agricultural uses in dry lands from geologic point of view using GIS a case study from Jordan. Indonesian Journal on Geoscience, North America, 2(2). https://doi.org/10.17014/ijog.2.2.63-76

Alharbi, O. M. L., Basheer, A. A. Khattab, R. A., \& Ali, I. (2018). Health and environmental effects of persistent organic pollutants. Journal of Molecular Liquids, 263, 442-453.

https://doi.org/10.1016/j.molliq.2018.05.029

Ali, I., Asim, M., \& Khan, T. A. (2013). Arsenite removal from water by electro-coagulation on zinc-zinc and copper-copper electrodes. International Journal of Environmental Science and Technology, 10, 377-384.

https://doi.org/10.1007/s13762-012-0113-Z

Ali, I., Alothman, Z. A., \& Alwarthan, A. (2017). Supra molecular mechanism of the removal of 17 - $\beta$-estradiol endocrine disturbing pollutant from water on functionalized iron nanoparticles. Journal of Molecular Liquids, 241, 123-129. https://doi.org/10.1016/j.molliq.2017.06.005

Al-Mashagbah, A. F. O., \& Al-Adamat, R. A. N. (2010). Mapping the land use/land cover changes in the basalt area between 1990 and 202005 using remote sensing and GIS. Jordan Journal of Civil Engineering, 4(3), 272-279. https://www.iiste.org/ Journals/index.php/JJCE/article/view/17919/18296

Al-Sallal, F. J., \& Al-Bilbisi, H. H. (2011). A GIS and remote sensing based integrated approach to detect land use/cover dynamics in Sahab district (Central Jordan). Abahth Al-Yarmouk. Humanities \& Social Sciences, 27(3), 2345-2362. http:// repository.yu.edu.jo/bitstream/123456789/2579/1/598839.pdf

Basheer, A. A. (2017). Chemical chiral pollution: Impact on the society and science and need of the regulations in the $21^{\text {st }}$ century. Chirality, 30(4), 402-406. https://doi.org/10.1002/chir.22808

Basheer, A. A., \& Ali, I. (2018). Stereoselective uptake and degradation of pesticide stereomers in water-sediment system. Chirality, 30(9), 1088-1095. https://doi.org/10.1002/chir.22989

Bender, F. (1974). Geology of Jordan. Contribution of the regional geology of the earth. Borntraeger, Berlin. https://www.worldcat.org/title/geology-of-jordan/oclc/1067003

De la Rosa, D., Cardona, F., \& Almorza, J. (1981). Crop yield predictions based on properties of soils in Sevilla, Spain. Geoderma, 25(3-4), 267-274. https://doi.org/10.1016/0016-7061(81)90040-9

Department of Statistics. (2014). Statistical year book. Government Publication, Amman.

http://dosweb.dos.gov.jo/products/statistical-yearbook2014/

Dunlap, R. E., \& Jorgenson, A. (2012). Environmental problems. In The Wiley-Blackwell Encyclopedia of Globalization ( $1^{\text {st }} \mathrm{ed}$.). Wiley. https://doi.org/10.1002/9780470670590.wbeog174

ElSheik, R. F. A., Ahmad, N., Shariff, A. R. M., Balasundra, S. K., \& Yahaya, S. (2010). An agricultural investment map based on geographic information system and multi-criteria method. Journal of Applied Sciences, 10(15), 1596-1602. https://doi.org/10.3923/jas.2010.1596.1602

Farhan, I. A., \& Al-Bakri, F. T. (2012). Use of GIS and remote sensing to assess soil erosion in an arid to semiarid basin in Jordan. In Proceedings of the International Conference on Sediment Transport: Modeling in Hydrological Watersheds and Rivers (pp. 145-152). Istanbul. https://www.researchgate.net/ publication/259360636_Use_of_GIS_and_remote_sensing to_assess_soil_erosion_in_arid_to_semiarid_basin_in_Jordan 
Food and Agriculture Organization of the United Nations. (1976). A framework for land evaluation (FAO Soils Bulletin, 32). Rome. http://www.fao.org/3/x5310e/x5310e00.htm

Food and Agriculture Organization of the United Nations. (1983). Guidelines: Land evaluation for rainfed agriculture (FAO Soils Bulletin, 52). Italy, Rome. http://www.fao.org/ fileadmin/templates/cpesap/C-RESAP_Info_package/Links/ Module_5/Land_ev_and_LUP.pdf

Food and Agriculture Organization of the United Nations. (1985). Guidelines: Land evaluation for irrigated agriculture (FAO Soils Bulletin, 55). Rome, Italy.

http://www.fao.org/3/X5648E/x5648e00.htm

Food and Agriculture Organization of the United Nations. (1993). Guidelines for land use planning (FAO Development Series 1). Rome. http://www.fao.org/3/t0715e/t0715e00.htm

Food and Agriculture Organization of the United Nations. (2007). Land evaluation towards a revised framework. Italy, Rome.

Gülersoy, A. E., \& Çelİk, M. A. (2017). Temporal change of land use in the Protection Basin of Tahtalı Dam (1990-2015), (Izmir, Turkey). Journal of Environmental Biology, 38(5), 1061-1067. https://doi.org/10.22438/jeb/38/5(SI)/GM-24

Gülersoy, A. E., Gümüş, N., Snmez, M. E., \& Gündüzoğlu, G. (2015). Relations between the land use and land capability classification in Küçük Menderes River Basin. Journal of Environmental Biology, 36(Spec No), 17-26.

https://pubmed.ncbi.nlm.nih.gov/26591877/

Hobler, M., Margane, A., Almomani, M., \& Subah, A. (2001). Groundwater resources of Northern Jordan, Vol. 4: Hydrogeological Features of Northern Jordan. Technical Cooperation Project "Advisory Services to the Water Authority of Jordan". BGR \& WAJ, BGR archive no. 112708:5. Amman.

Joerin, F., Thériault, M., \& Musy, A. (2001). Using GIS and outranking multicriteria analysis for land-use suitability assessment. International Journal of Geographical Information Science, 15(2), 153-174. https://doi.org/10.1080/13658810051030487

Lambin, E. F., \& Meyfroidt, P. (2010). Land use transitions: Socio-ecological feedback versus socio-economic change. Land Use Policy, 27(2), 108-118.

https://doi.org/10.1016/j.landusepol.2009.09.003

Li, J. P., \& Chou, J. F. (1997). Existence of atmosphere attractor. Science in China Series D: Earth Sciences, 40, 215-224. https://doi.org/10.1007/BF02878381

Lu, D., \& Weng, Q. (2007). A survey of image classification methods and techniques for improving classification performance. International Journal of Remote Sensing, 28(5), 823870. https://doi.org/10.1080/01431160600746456

Margane, A., Hobler, H., \& Subah, A. (1999). Mapping of groundwater vulnerability and hazards to groundwater in the Irbid area, N Jordan. Zeischrift für Angewandte Geologie, 45(4), 75-187. https://www.geozentrum-hannover.de/EN/ Themen/Wasser/Produkte/Downloads/zag45-4_gwvuln_irbid.pdf? _ blob=publicationFile\&v=2

Mazahreh, S., Bsoul, M., \& Hamoor, D. A. (2018). GIS approach for assessment of land suitability for different land use alternatives in semi-arid environment in Jordan: Case study ( $\mathrm{Al}$ Gadeer Alabyad-Mafraq). Information Processing in Agriculture, 6(1), 91-108. https://doi.org/10.1016/j.inpa.2018.08.004

Ministry of Water and Irrigation, Jordan. (2010). National water master plan of Jordan, GTZ, Framework of coopera- tion between the Ministry of Water and Irrigation and GTZ (pp. 1-97). Amman, Jordan.

Ministry of Water and Irrigation, Jordan. (2016). National water strategy of Jordan, 2016-2025. Amman, Jordan.

Mohammad, A. H., Almomani, T., \& Alhejoj, I. (2015). Groundwater vulnerability for the surface outcropping aquifers in Jordan. Journal of Environmental Protection, 6(3), 250-258. https://doi.org/10.4236/jep.2015.63025

Mohammad, A. H., Hazimeh, W., Shatanawi, K., \& Abualhaija, M. (2020). Quantity not quality: promoting sustainable wastewater practices in Jordan. Water Policy, 22(3), 435-448. https://doi.org/10.2166/wp.2020.195

Mohammad, A. H., Jung, H. C., Odeh, T., Bhuiyan, C., \& Hussein, H. (2018). Understanding the impact of droughts in the Yarmouk Basin, Jordan: Monitoring droughts through meteorological and hydrological drought indices. Arabian Journal of Geosciences, 11(5), 103. https://doi.org/10.1007/s12517-018-3433-6

Odeh, T., Boulad, N., Abed, O., Abu Yahya, A., Khries, N., \& Abu-Jaber, N. (2017). The influence of geology on landscape typology in Jordan: Theoretical understanding and planning implications. Land, 6(3), 51.

https://doi.org/10.3390/land6030051

Odeh, T., Geyer, S., Rödiger, T., Siebert, C., \& Schirmer, M. (2013). Groundwater chemistry of strike slip faulted aquifers: The case study of Wadi Zerka Ma'in aquifers, north east of the Dead Sea. Environmental Earth Sciences, 70, 393-406. https://doi.org/10.1007/s12665-012-2135-8

Odeh, T., Mohammad, A. H., Hussein, H., Ismail, M., \& Almomani, T. (2019). Over-pumping of groundwater in Irbid governorate, northern Jordan: A conceptual model to analyze the effects of urbanization and agricultural activities on groundwater levels and salinity. Environmental Earth Sciences, 78, 40. https://doi.org/10.1007/s12665-018-8031-0

Perdew, L. (2014). Understanding Jordan today (pp. 17-18). Mitchell Lane Publishers, Inc.

Rababa'a, M., \& Al-Bakri, J. (2006). Mapping the Dead Sea basin from Landsat TM satellite imagery. Dirasat, Agricultural Science, 33(2), 103-113.

Saraf, K., Choudhury, R., Roy, B., Sarma, B., Vijay, S., \& Choudhury, S. (2004). GIS based surface hydrological modelling in identification of groundwater recharge zones. International Journal of Remote Sensing, 25(24), 5759-5770. https://doi.org/10.1080/0143116042000274096

Sys, C. (1975). Guidelines for the interpretation of land properties for some general land utilization types. Soils Bulletin, 29.

Sys, C., Van Ranst, E., Debaveye, J., \& Beernarent, F. (1993). Land evaluation. Part III: Crop requirements. International training center for postgraduate soil scientist. Ghent University, Ghent.

US Department of Agriculture (USDA). (1993). Soil survey manual. Soil Science Division Staff. Handbook No. 18. U.S. Government Printing Office, Washington. https://www.nrcs.usda.gov/ wps/portal/nrcs/detailfull/soils/ref/?cid=nrcs142p2_054262

US Geological Survey web site. (n.d.). https://landsat.usgs.gov/ lands

Yohannes, H., Soromessa, T., Argaw, M., \& Dewan, A. (2020). Changes in landscape composition and configuration in the Beressa watershed, Blue Nile basin of Ethiopian Highlands: historical and future exploration. Heliyon, 6(9), e04859. https://doi.org/10.1016/j.heliyon.2020.e04859 